\title{
Experimental analysis on steel reinforced glass beams at different temperatures
}

\author{
P.J.S. Cruz and I. Valente \\ ISISE, University of Minho, Guimarães, Portugal \\ P.L.L. Carvalho, B. Marinho and S. Ribeiro \\ University of Minho, Guimarães, Portugal
}

\begin{abstract}
Whereas glass components were used as infill elements in the past, contemporary architectural concepts include glass components as load-bearing elements. Recent architectural trends and technological developments have brought about unprecedented opportunities in the use of glass in buildings. The increasingly daring structural applications of glass will continue to drive the development of structural glass elements with high post-failure resistances.

The present work aims to explore the concepts of structural performance of glass beams and the effectiveness of an embedded steel reinforcement system. The reinforcement system consists in embedding perforated stainless steel plates in the lamination process.

The experimental study focuses on the effect of thermal actions and compares the use of soft foils and stiff foils (temperature ranging from approximately $16{ }^{\circ} \mathrm{C}$ to $85^{\circ} \mathrm{C}$ ).
\end{abstract}

\section{INTRODUCTION}

In the last few years several concepts have been developed which may be described as hybrid elements composed by the combination of glass and other materials. Glass-wood, glass-steel, and glass-reinforced concrete hybrids - mostly beams - have been analysed (Bucak et al. 2009, Cruz. \& Pequeno 2008, Louter et al. 2009, Netusil \& Eliasova 2011, Ungermann \& Preckwinkel 2010, Weller et al. 2009, Wellershoff \& Sedlacek 2003).

Rather than minimizing the probability of glass failure, the reinforced glass beam concept addition of a reinforcement section to the glass beam - aims for high residual resistance of structural glass beams by minimizing the consequences of glass failure. Even if all glass layers of the beam laminate are broken, the beam should not collapse and should still be able to carry load.

To counteract the reduced residual strength of laminated glass made out of fully tempered glass and the viscoelastic behaviour of the polymer interlayers, Feirabend (2008) proposed to embed a metal reinforcement (stainless steel wire meshes, thin perforated metal sheets and fabrics of high strength fibres). If the temperature of the interlayer exceeds the glass transition temperatures $T_{G}\left(T_{G, P V B}=10-15^{\circ} \mathrm{C} ; T_{G, S G P}=55^{\circ} \mathrm{C}\right)$ the strength and stiffness will be reduced. Particularly the shear stiffness of the interlayer will be reduced, affecting the composite action of the laminated glass when no pane is broken (Feirabend 2008). 


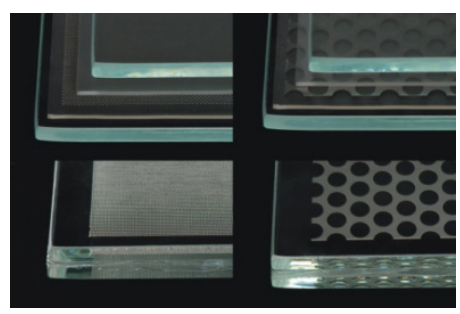

(a) Overview of reinforced laminated glass samples.

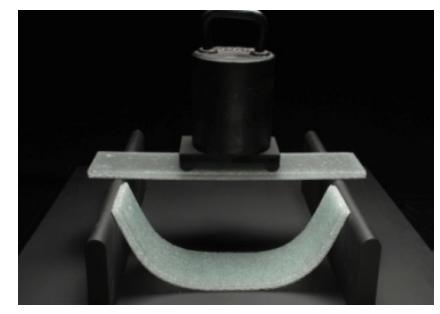

b) Post-breakage behaviour of tempered laminated glass with and without steel-wire mesh reinforcement.

Figure 1. Metal wire mesh or perforated thin metal plate reinforcement embedded in the interlayer of laminated glass (Feirabend 2008).

Carvalho et al. (2011) analysed the adhesive strength of pull-out specimens with perforated and non-perforated embedded stainless steel plates (Figure 2). The experimental investigations have been performed by pulling out perforated and non-perforated steel plates, from the laminated glass panel, at constant displacement rates. The results showed different behaviours with PVB and SGP interlayers.

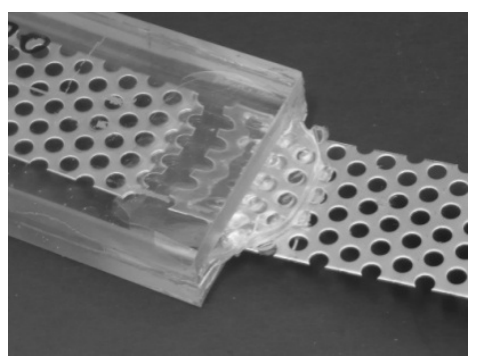

Figure 2. A specimen after a pull-out test (Carvalho et al. 2011).

Santarsiero et al. (2013) studied the effect of temperature in the behaviour of pull-out tests of embedded non-perforated steel plates. Carvalho et al. (2013) analysed the efficacy of using the extended embedded steel plates to splice glass beams. Bending tests have been carried out at different temperatures $\left(20^{\circ} \mathrm{C}, 50^{\circ} \mathrm{C}\right.$ and $\left.80^{\circ} \mathrm{C}\right)$.

The present work aims to explore the effectiveness of an embedded steel reinforcement system and to assess how this solution enhances the safety and the ductility of the beams under bending and shear actions.

\section{SPECIMEN PREPARATION}

The tested specimens consist of small rectangular annealed glass panes $(10 \mathrm{~mm}$ thickness, $100 \mathrm{~mm}$ high and $1100 \mathrm{~mm}$ length) combined with rectangular stainless-steel plates, laminated with a transparent interlayer (Figure 3).

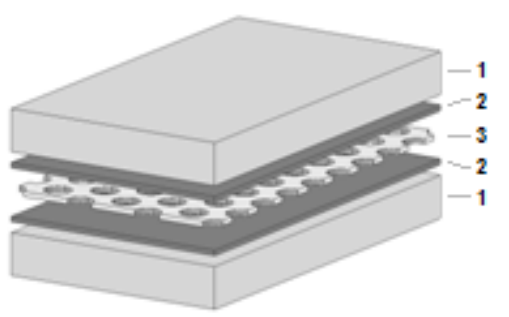

1 - Glass monolithic

2 - Interlayer (PVB or SG)

3 - perforated metal plate with $1 \mathrm{~mm}$

Figure 3. Embedding perforated stainless steel plates in the glass lamination process. 
It was used 1,52 mm Vanceva PVB and 1,52 mm SGP interlayers. The perforated steel plate used in the experimental investigation has $1 \mathrm{~mm}$ thickness and is made of AISI 304 stainless steel. The R5T8 pattern is characterized by having $5 \mathrm{~mm}$ diameter holes disposed diagonally at an angle of $60^{\circ}$, distancing $8 \mathrm{~mm}$ from centre to centre. This type of pattern has $35,4 \%$ of the surface perforated.

The specimens were placed inside a smart blanket system inserted in an autoclave as illustrated in Figure 4, where they were heated to a temperature of $125-135^{\circ} \mathrm{C}$ for a period of three hours.

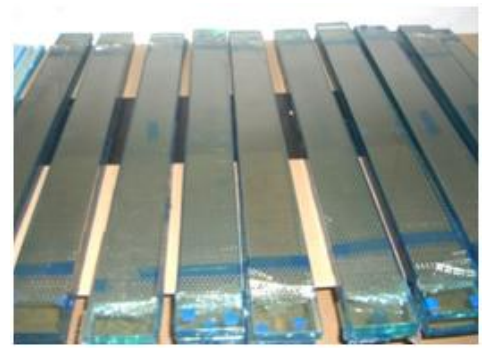

a) Specimens before lamination.

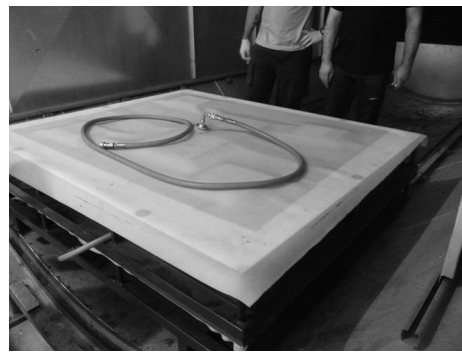

b) Specimens inside the smart c) Autoclave. blanket system.

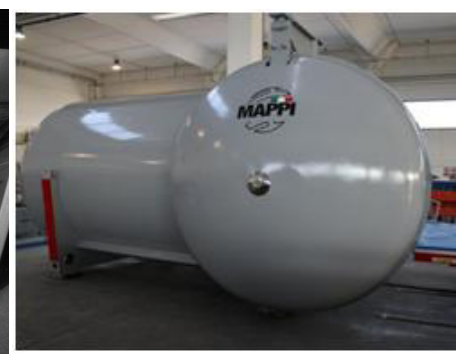

Figure 4. The lamination process.

\section{TEST PROCEDURES}

Figure 5 illustrates the setup and of the four-point bending tests performed at the Laboratory of Construction Technology of the School of Architecture of the University of Minho.

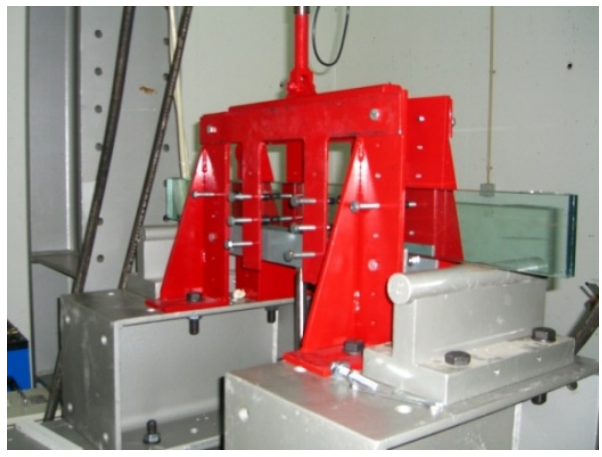

a) At room temperature.

Figure 5. Four-point bending tests.

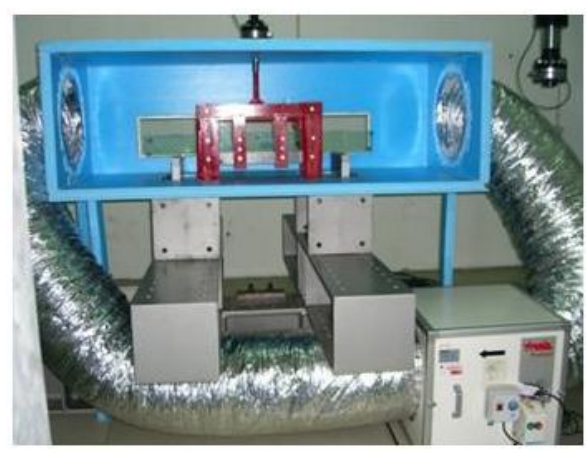

b) In a thermal chamber (without the front cover).

The specimens were simply supported in steel rollers. The load configuration is illustrated in Figure 6. All tests were carried out with deformation control at the beam mid span and measurements of applied load value (displacement rate of $1 \mathrm{~mm} / \mathrm{s}$ ).

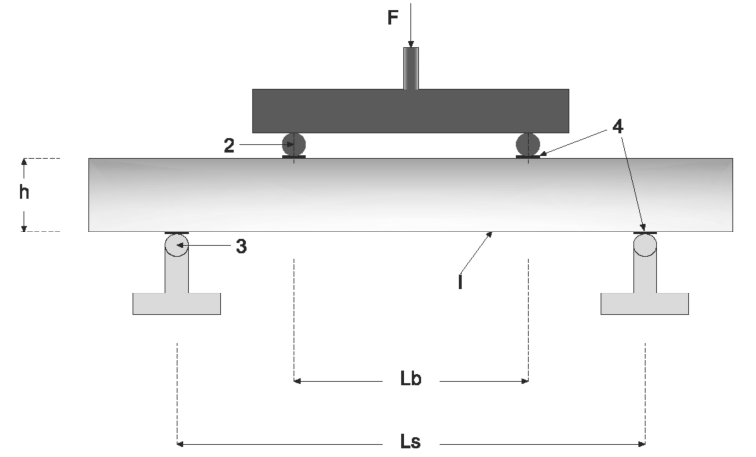

1 - Glass beam

2 - Device to distribute the loading

3 - Support

4 - Rubber layer

$\mathrm{Lb}=400 \mathrm{~mm} ; \mathrm{h}=100 \mathrm{~mm}$

$\mathrm{Ls}=800 \mathrm{~mm}$

Figure 6. Load configuration. 
The dimensions of the thermal chamber were carefully chosen to make possible a good drive of the heated air flow. Therefore, it was decided to build a box with a length of $1,90 \mathrm{~m}$, a high of $0,65 \mathrm{~m}$ and a depth of $0,80 \mathrm{~m}$. The ventilation system was provided by a company specialized in HVAC systems. The module of resistances was installed inside the fan, positioned in the opening of the air reception. This position causes the air return allowing the air previously heated to warm up again in order to achieve the desired temperature. The thermostat was placed in the upper interior part of the thermal chamber. Its main function is to measure the temperature inside the chamber, turning on/off the resistances when necessary and maintaining the space at a given preset temperature, turning-off automatically to avoid overheating.

Figure 7 illustrates the temperature during the tests. As stated before the temperature ranges from a minimum of $16^{\circ} \mathrm{C}$ to a maximum of $85^{\circ} \mathrm{C}$. Those figures clearly demonstrate the difficulty in maintaining constant the high temperatures.

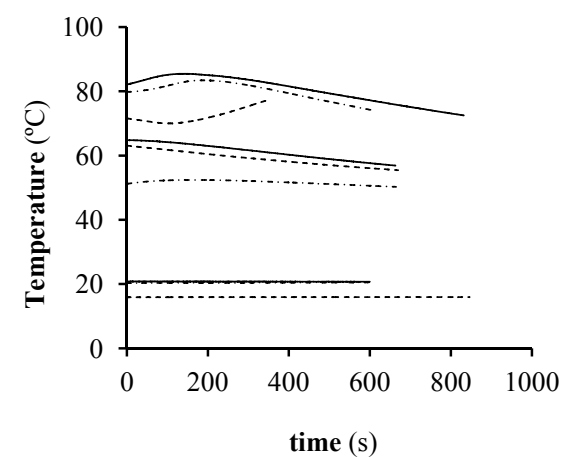

a) Laminated glass beams (PVB).

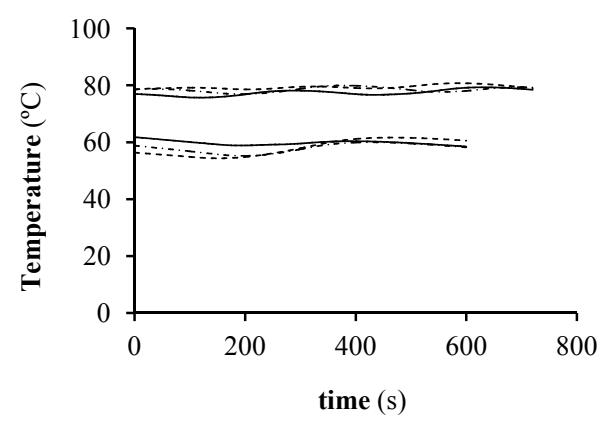

c) Reinforced laminated glass beams (PVB).

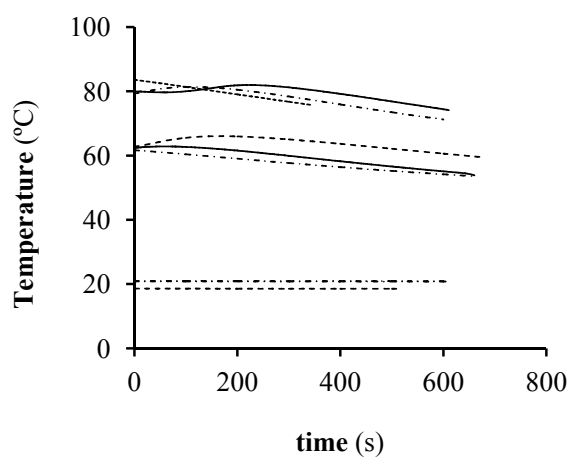

b) Laminated glass beams (SGP).

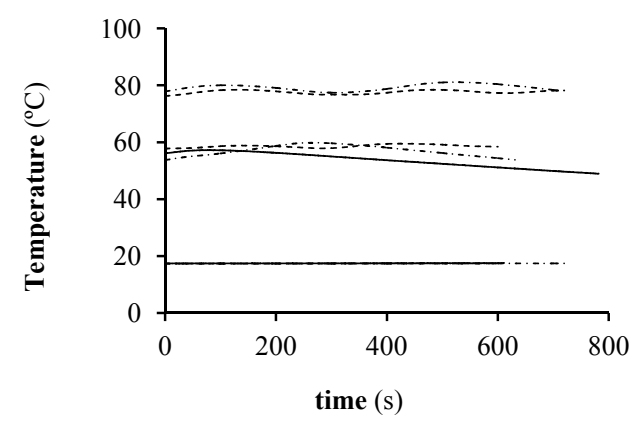

d) Reinforced laminated glass beams (SGP).

Figure 7. Variation of temperature during the tests.

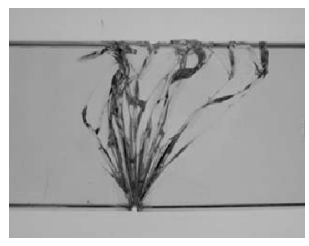

a) PVB at room temperature.

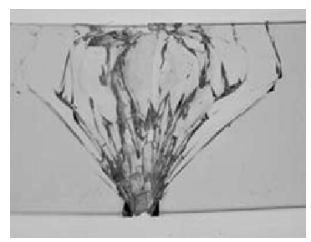

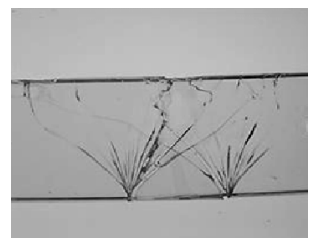

b) PVB at aproximatly $60^{\circ} \mathrm{C}$.

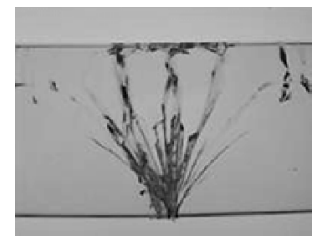

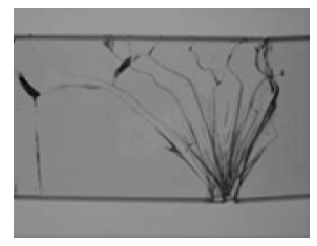

c) PVB at aproximatly $80^{\circ} \mathrm{C}$.

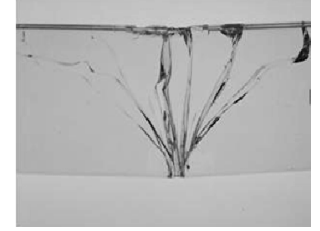

d) SGP at at room temperature. e) SGP at at aproximatly $60{ }^{\circ} \mathrm{C}$. f) SGP at at aproximatly $80{ }^{\circ} \mathrm{C}$. Figure 8. Cracked patterns of glass beams. 


\section{RESULTS}

\subsection{Glass beams}

Table 1 shows a summary of the results of the 18 bending tests of laminated glass beams ( 3 for each envisaged temperature).

The crack patterns are very similar in both glass panes, i.e. cracks are located in the same section, whereas in the beams laminated with PVB the cracks have not the same location in both glass panes, as illustrated in Figure 8.

Table 1. Experimental results of the bending tests of laminated glass beams.

\begin{tabular}{|c|c|c|c|c|c|c|c|c|c|c|c|}
\hline \multirow{3}{*}{\multicolumn{2}{|c|}{ Specimen }} & \multicolumn{4}{|c|}{ Temperature } & \multicolumn{3}{|c|}{ Max. Load } & \multicolumn{3}{|c|}{ Disp. at Max. Load } \\
\hline & & \multirow{2}{*}{\multicolumn{2}{|c|}{$\begin{array}{c}\text { mean } \\
\left({ }^{\circ} \mathrm{C}\right)\end{array}$}} & \multirow{3}{*}{$\frac{\text { min. }}{\frac{\left({ }^{\circ} \mathrm{C}\right)}{15,83}}$} & \multirow{3}{*}{$\begin{array}{c}\max . \\
\left({ }^{\circ} \mathrm{C}\right) \\
16,02\end{array}$} & & \multirow{2}{*}{$\frac{\text { mean }}{(\mathrm{kN})}$} & \multirow{2}{*}{$\begin{array}{r}\text { st.dev } \\
(\mathrm{kN})\end{array}$} & \multirow{2}{*}{$(\mathrm{mm})$} & \multirow{2}{*}{$\frac{\text { mean }}{(\mathrm{mm})}$} & \multirow{2}{*}{$\frac{\text { st.dev }}{(\mathrm{mm})}$} \\
\hline & & & & & & & & & & & \\
\hline \multirow{9}{*}{ PVB } & 1 & \multirow{3}{*}{19,03} & 15,93 & & & & \multirow{3}{*}{14,40} & \multirow{3}{*}{1,25} & & \multirow{3}{*}{2,17} & \multirow{3}{*}{0,13} \\
\hline & 2 & & 20,41 & 20,26 & 20,57 & 13,01 & & & 2,14 & & \\
\hline & 3 & & 20,76 & 20,66 & 20,86 & 14,73 & & & 2,31 & & \\
\hline & 4 & \multirow{3}{*}{54,52} & 51,72 & 48,63 & 55,96 & 12,57 & \multirow{3}{*}{12,09} & \multirow{3}{*}{0,75} & 3,62 & \multirow{3}{*}{3,39} & \multirow{3}{*}{0,55} \\
\hline & 5 & & 51,41 & 49,73 & 52,43 & 12,47 & & & 2,76 & & \\
\hline & 6 & & 60,44 & 55,65 & 64,80 & 11,23 & & & 3,78 & & \\
\hline & 7 & \multirow{3}{*}{77,51} & 72,18 & 69,98 & 77,08 & 13,80 & \multirow{3}{*}{11,73} & \multirow{3}{*}{3,27} & 2,65 & & \\
\hline & 8 & & 80,05 & 74,21 & 83,44 & 7,96 & & & 1,70 & \multirow{2}{*}{2,12} & \multirow[t]{2}{*}{0,49} \\
\hline & 9 & & 80,31 & 72,48 & 85,46 & 13,44 & & & 2,00 & & \\
\hline \multirow{9}{*}{ SGP } & 1 & \multirow{3}{*}{20,10} & 18,56 & 18,47 & 18,65 & 16,93 & \multirow{3}{*}{16,09} & \multirow{3}{*}{0,76} & 2,12 & & \\
\hline & 2 & & 20,80 & 20,71 & 20,89 & 15,46 & & & 2,03 & 2,16 & 0,15 \\
\hline & 3 & & 20,93 & 20,83 & 21,02 & 15,87 & & & 2,32 & & \\
\hline & 4 & & 63,27 & 58,74 & 66,06 & 12,24 & & & 4,52 & & \\
\hline & 5 & 59,84 & 57,07 & 53,00 & 61,68 & 11,82 & 12,62 & 1,05 & 1,70 & 3,01 & 1,42 \\
\hline & 6 & & 59,19 & 53,82 & 62,85 & 13,81 & & & 2,80 & & \\
\hline & 7 & & 76,79 & 70,19 & 83,62 & 11,06 & & & 1,77 & & \\
\hline & 8 & 77,88 & 77,54 & 71,21 & 81,41 & 13,73 & 12,26 & 1,36 & 2,20 & 2,17 & 0,39 \\
\hline & 9 & & 79,31 & 74,11 & 81,98 & 12,00 & & & 2,55 & & \\
\hline
\end{tabular}

\subsection{Reinforced glass beams}

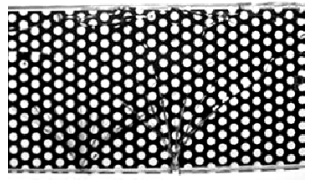

a) PVB at aproximatly $60^{\circ} \mathrm{C}$.

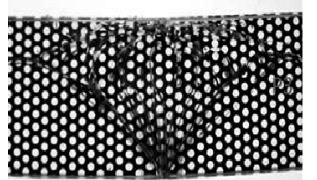

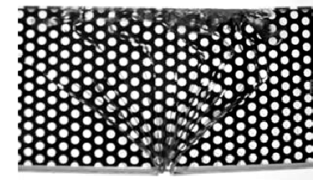

b) PVB at aproximatly $80^{\circ} \mathrm{C}$.

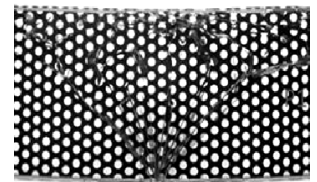

c) SGP at at room temperature. d) SGP at at aproximatly $60^{\circ} \mathrm{C}$. e) SGP at at aproximatly $80^{\circ} \mathrm{C}$.

Figure 9. Cracked patterns of reinforced glass beams.

In case of glass fracture the reinforcement transfers the tensile force over the crack. The tensile force in the reinforcement combined with a compression force in the non-cracked compression zone generates an internal load-carrying mechanism which enables the beam to still carry load even if all glass layers are cracked.

As can be observed in Figure 9c the reinforced beams exhibited a distributed crack pattern when tested at room temperature, which clearly demonstrate the efficacy of the reinforcement, although this effect is much more accentuated in the beams laminated with SGP, due to its 
higher resistance. At higher temperatures the cracks become more concentrated in the central span. Furthermore, the crack patterns are very similar in both glass panes, i.e. cracks are located in the same section.

Table 2 shows a summary of the results of the 14 bending tests of reinforced laminated glass beams.

Table 2. Experimental results of the bending tests of reinforced laminated glass beams.

\begin{tabular}{|c|c|c|c|c|c|c|c|c|c|c|c|}
\hline \multirow{3}{*}{\multicolumn{2}{|c|}{ Specimen }} & \multicolumn{4}{|c|}{ Temperature } & \multicolumn{3}{|c|}{ Max. Load } & \multicolumn{3}{|c|}{ Disp. at max. Load } \\
\hline & & \multirow{2}{*}{\multicolumn{2}{|c|}{$\frac{\text { mean }}{\left({ }^{\circ} \mathrm{C}\right)}$}} & & \multirow{2}{*}{$\frac{\max }{\left({ }^{\circ} \mathrm{C}\right)}$} & & \multirow{2}{*}{$\begin{array}{c}\text { mean } \\
(\mathrm{kN})\end{array}$} & \multirow{2}{*}{$\begin{array}{c}\text { st.dev } \\
(\mathrm{kN})\end{array}$} & \multirow{2}{*}{$(\mathrm{mm})$} & \multirow{2}{*}{$\begin{array}{ll}\text { mean } \\
(\mathrm{mm})\end{array}$} & \multirow{2}{*}{$\begin{array}{l}\text { st.dev } \\
(\mathrm{mm})\end{array}$} \\
\hline & & & & & & $(\mathrm{kN})$ & & & & & \\
\hline \multirow{6}{*}{ PVB } & 1 & \multirow{3}{*}{58,60} & 58,12 & 54,33 & 61,67 & 13,67 & \multirow{3}{*}{12,38} & \multirow{3}{*}{1,43} & 0,96 & \multirow{3}{*}{1,25} & \multirow{3}{*}{0,37} \\
\hline & 2 & & 57,91 & 55,16 & 60,01 & 10,85 & & & 1,13 & & \\
\hline & 3 & & 59,78 & 58,46 & 61,78 & 12,61 & & & 1,67 & & \\
\hline & 4 & \multirow{3}{*}{78,44} & 79,40 & 78,52 & 80,78 & 10,61 & \multirow{3}{*}{12,06} & \multirow{3}{*}{2,32} & 1,25 & \multirow{3}{*}{1,20} & \\
\hline & 5 & & 78,47 & 76,88 & 79,96 & 14,74 & & & 1,27 & & \multirow[t]{2}{*}{0,10} \\
\hline & 6 & & 77,45 & 75,65 & 79,35 & 10,85 & & & 1,09 & & \\
\hline \multirow{8}{*}{ SGP } & 1 & \multirow{3}{*}{17,41} & 17,38 & 17,26 & 17,49 & 16,53 & \multirow{3}{*}{16,40} & \multirow{3}{*}{1,47} & 1,34 & \multirow{3}{*}{1,83} & \multirow{3}{*}{0,62} \\
\hline & 2 & & 17,40 & 17,28 & 17,50 & 17,80 & & & 1,63 & & \\
\hline & 3 & & 17,44 & 17,54 & 17,35 & 14,87 & & & 2,53 & & \\
\hline & 4 & \multirow{3}{*}{56,44} & 58,63 & 57,76 & 59,54 & 12,15 & \multirow{3}{*}{13,50} & \multirow{3}{*}{1,22} & 1,15 & \multirow{3}{*}{1,32} & \multirow{3}{*}{0,53} \\
\hline & 5 & & 57,05 & 53,71 & 59,88 & 13,81 & & & 0,89 & & \\
\hline & 6 & & 53,65 & 48,92 & 57,27 & 14,52 & & & 1,92 & & \\
\hline & 7 & \multirow{2}{*}{78,45} & 77,62 & 76,23 & 78,48 & 12,93 & 1266 & 038 & 1,19 & 004 & 035 \\
\hline & 8 & & 79,29 & 77,39 & 81,14 & 12,39 & 12,66 & 0,38 & 0,69 & 0,94 & 0,35 \\
\hline
\end{tabular}

The structural response in terms of load versus relative displacement is presented in figures 10 to 12 .

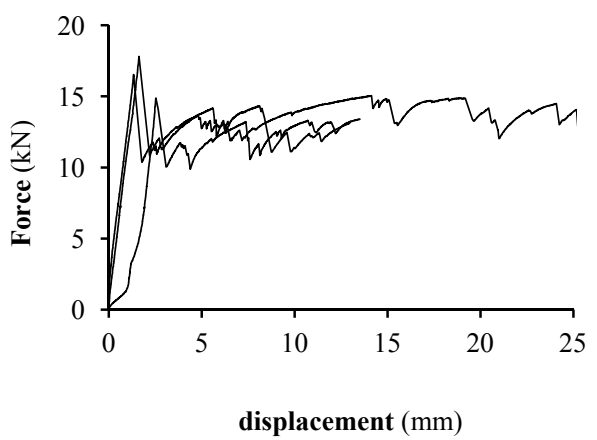

a) Reinforced laminated glass beams.

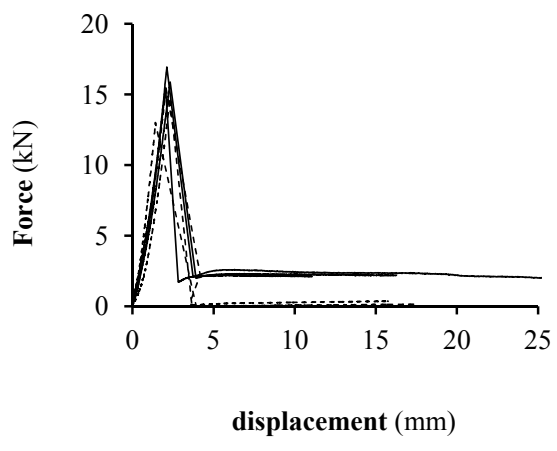

b) Laminated glass beams.

Figure 10. Force-deflection diagrams at room temperature.

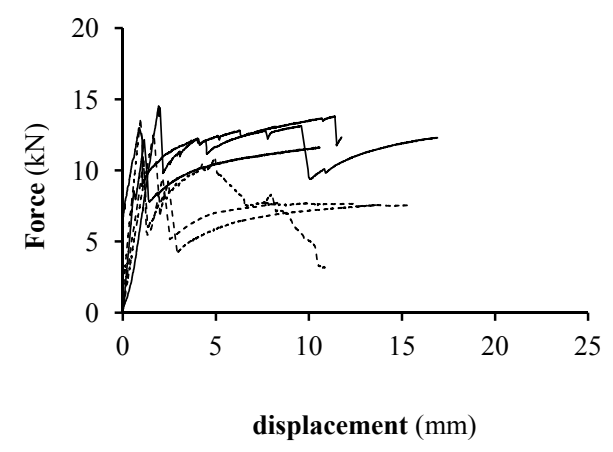

a) Reinforced laminated glass beams.

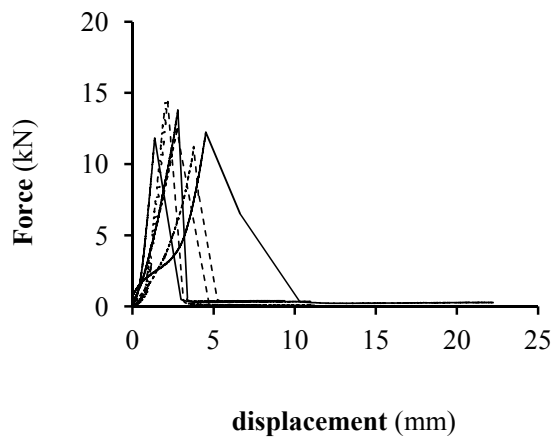

b) Laminated glass beams.

Figure 11 . Force-deflection diagrams at approximately $60^{\circ} \mathrm{C}$. 


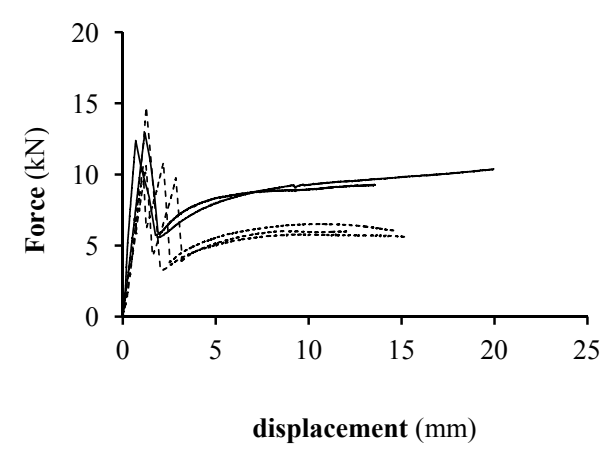

a) Reinforced laminated glass beams.

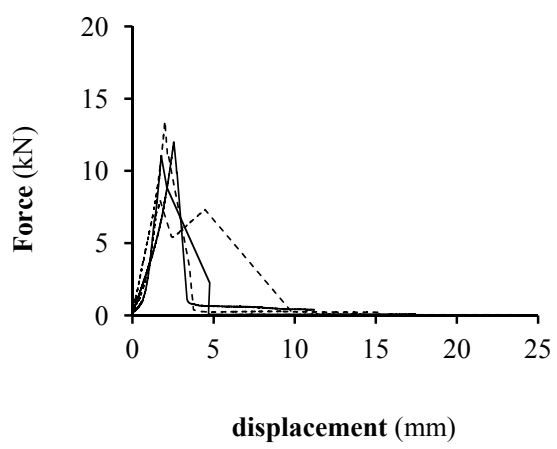

b) Laminated glass beams.

Figure 12 . Force-deflection diagrams at approximately $80^{\circ} \mathrm{C}$.

\section{CONCLUSIONS}

The solution of embedding perforated steel plates in the intermediate layers of laminated glass is, by several reasons, emerging as one of the most promising techniques to increase significantly the safety and the ductility of load-carrying glass elements.

This reinforcement-interlayer-matrix combines the high tensile and high extensional stiffness of the reinforcement with the high degree of adhesion of the synthetic interlayer material.

The effects of temperature are crucial for the safety performance of the reinforced glass beam, as it influences the bond between glass and reinforcement and the structural functioning of the system.

Further research is needed to improve the efficacy of the thermal chamber to achieve a constant temperature during the loading tests, in order to obtain more predictable and reliable results and to make possible the development of a comprehensive set of rational guidelines for design and specification of those structural elements. However the results obtained showed that it is possible to increase the residual strength of glass panes in the damaged state, acquiring residual strength throughout the temperature range.

\section{ACKNOWLEDGEMENTS}

This work is funded by FEDER Funds, through the Operational Programme Competitiveness Factors - COMPETE, and Portuguese Funds, through FCT - Foundation for Science and Technology, under the project PTDC/ECM/116609/2010, "S-GLASS: Structural Performance and Design Rules of Glass Beams Externally Reinforced".

In addition, The COST Action TU0905 "Structural Glass - Novel Design Methods and Next Generation Products" is also acknowledged.

\section{REFERENCES}

Bucak, O., Bues, M., Illguth, M. Geiß, P.L. \& Kötter, M.P. 2009. Bonded steel glass hybrid beams, Glass Performance Days: Proc. intern. symp., Tampere, 12-15 June 2009: 318-320.

Carvalho, P.L.L., Cruz, P.J.S. \& Veer F.A. 2011. Perforated steel plate to laminated glass adhesive properties, Glass Performance Days: Proc. intern. symp., Tampere, 16-17 June: 281-285.

Carvalho, P.L.L., Cruz, P.J.S. \& Veer, F.A. 2013. Connecting through reinforcement - Experimental analysis of the temperature and time dependent behavior, COST Action TU0905 - Structural Glass: Proc. intern. symp., Poreč, 18-19April 2013. Balkema.

Cruz, P.J.S. \& Pequeno, J.M. 2008. Timber-Glass Composite Beams: Mechanical Behaviour \& Architectural Solutions, Challenging Glass: Proc. intern. symp., Delft, $22-23$ May 2008: 439-448.

Feirabend, S. 2008. Reinforced Laminated Glass, Challenging Glass: Proc. intern. symp., Delft, 22-23 May 2008. 
Louter, C., Bos, F., Callewaert, D. \& Veer, F. 2009. Performance of SentryGlas-laminated metalreinforced glass beams at 23, -20 and $60^{\circ} \mathrm{C}$, Glass Performance Days: Proc. intern. symp., Tampere, 12-15 June 2009: 334-339.

Netusil, M. \& Eliasova, M. 2001. Hybrid steel-glass beams with polymer adhesive, Glass Performance Days: Proc. intern. symp., Tampere, 16-17 June: 294-298.

Santarsiero, M., Carvalho, P.L.L., Louter, C. \& Cruz, P.J.S. 2013. Experimental and numerical studies on embedded metal-to-glass connections at different temperatures, COST Action TU0905 - Structural Glass: Proc. intern. symp., Poreč, 18-19 April 2013. Balkema.

Ungermann, D. \& Preckwinkel, E. 2010. Structural Behaviour of Hybrid Steel-Glass Beams, Challenging Glass 2: Proc. intern. symp., Delft, 20-21 May 2010: 485-495.

Weller, B., Weimar, T., Krampe, P. \& Walther, A. 2009. Glass-Steel Beams - Development of Hybrid Structures, Glass Performance Days: Proc. intern. symp., Tampere, 12-15 June 2009: 435-439.

Wellershoff, F. \& Sedlacek, G. 2003. Structural Use of Glass in Hybrid Elements: Steel-Glass-Beams, Glass-GFRP-Plates, Glass Processing Days: Proc. intern. symp., Tampere: pp. 268-270. 